\title{
Hepatocyte specific expression of an oncogenic variant of $\beta$-catenin results in lethal metabolic dysfunction in mice
}

\author{
Ursula J. Lemberger ${ }^{1,2}$, Claudia D. Fuchs ${ }^{2}$, Christian Schöfer $^{3}$, Andrea Bileck ${ }^{4}$, \\ Christopher Gerner ${ }^{4}$, Tatjana Stojakovic ${ }^{5}$, Makoto M. Taketo ${ }^{6}$, Michael Trauner $^{2}$, \\ Gerda Egger ${ }^{1,7}$ and Christoph H. Österreicher ${ }^{8}$ \\ ${ }^{1}$ Clinical Institute of Pathology, Medical University of Vienna, Vienna, Austria \\ ${ }^{2}$ Hans Popper Laboratory for Molecular Hepatology, Department of Internal Medicine, Medical University of Vienna, Vienna, Austria \\ ${ }^{3}$ Department of Cell and Developmental Biology, Medical University of Vienna, Vienna, Austria \\ ${ }^{4}$ Department of Analytical Chemistry, Faculty of Chemistry, University of Vienna, Vienna, Austria \\ ${ }^{5}$ Clinical Institute of Medical and Chemical Laboratory Diagnostics, Medical University of Graz, Graz, Austria \\ ${ }^{6}$ Division of Experimental Therapeutics, Graduate School of Medicine, Kyoto University, Kyoto, Japan \\ ${ }^{7}$ Ludwig Boltzmann Institute Applied Diagnostics, Vienna, Austria \\ ${ }^{8}$ Institute of Pharmacology, Medical University Vienna, Vienna, Austria \\ Correspondence to: Ursula J. Lemberger, email: ursula.lemberger@meduniwien.ac.at, ursula.lemberger@gmx.at \\ Keywords: Wnt signaling pathway; liver cancer; lipid metabolism; glucose metabolism; mitochondrial disorder \\ Received: August 31, $2017 \quad$ Accepted: January 25, $2018 \quad$ Published: January 30, 2018 \\ Copyright: Lemberger et al. This is an open-access article distributed under the terms of the Creative Commons Attribution License \\ 3.0 (CC BY 3.0), which permits unrestricted use, distribution, and reproduction in any medium, provided the original author and \\ source are credited.
}

\section{ABSTRACT}

Background: Wnt/ $\beta$-catenin signaling plays a crucial role in embryogenesis, tissue homeostasis, metabolism and malignant transformation of different organs including the liver. Continuous $\beta$-catenin signaling due to somatic mutations in exon 3 of the Ctnnb1 gene is associated with different liver diseases including cancer and cholestasis.

Results: Expression of a degradation resistant form of $\beta$-catenin in hepatocytes resulted in $100 \%$ mortality within 31 days after birth. Ctnnb1 ${ }^{c A}$ hep mice were characterized by reduced body weight, significantly enlarged livers with hepatocellular fat accumulation around central veins and increased hepatic triglyceride content. Proteomics analysis using whole liver tissue revealed significant deregulation of proteins involved in fat, glucose and mitochondrial energy metabolism, which was also reflected in morphological anomalies of hepatocellular mitochondria. Key enzymes involved in transport and synthesis of fatty acids and cholesterol were significantly deregulated in livers of Ctnnb1 ${ }^{c A}$ hep mice. Furthermore, carbohydrate metabolism was substantially disturbed in mutant mice.

Conclusion: Continuous $\beta$-catenin signaling in hepatocytes results in premature death due to severe disturbances of liver associated metabolic pathways and mitochondrial dysfunction.

Methods: To investigate the influence of permanent $\beta$-catenin signaling on liver biology we analyzed mice with hepatocyte specific expression of a dominant stable form of $\beta$-catenin (Ctnnb1 ${ }^{c A}$ hep) and their WT littermates by serum biochemistry, histology, electron microscopy, mRNA profiling and proteomic analysis of the liver. 


\section{INTRODUCTION}

The role of $\beta$-catenin has been extensively investigated, highlighting its importance for organogenesis, pattern formation, cell proliferation, tissue regeneration and apoptosis in different organs including the liver. Along these lines it has been shown that $\beta$-catenin is temporally active during liver development and is essential for hepatic morphogenesis and metabolic zonation $[1,2]$. In adult liver $\beta$-catenin is rather inactive but remains an important regulator of liver homeostasis [3].

Hepatocyte specific deletion of $\beta$-catenin in mice $\left(C t n n b 1^{\Delta h e p}\right)$ results in underdeveloped livers characterized by immature hepatocytes, canalicular abnormalities, bile secretion defects and hence cholestasis and fibrosis [4-6]. Moreover, Ctnnb $1^{\Delta \text { hep }}$ mice display impaired liver regeneration after partial hepatectomy $[7,8] . \mathrm{Wnt} / \beta$ catenin signaling is responsible for the heterogeneity of hepatocytes, which results in a zonation with respect to metabolic processes. Periportal hepatocytes are predominantly involved in gluconeogenesis and $\beta$-oxidation, while hepatocytes located around central veins are responsible for glycolysis and lipogenesis. Close interaction between neighboring zones warrants quick and flexible adaption in response to different demands and ensures metabolic homeostasis $[9,10]$. Disturbance of the Wnt signaling pathway affects the identity of hepatocytes resulting in perturbation of zonation and hence in metabolic liver disease [11-13].

Evidently, Ctnnb1 $1^{\Delta h e p}$ mice are more susceptible to develop steatohepatitis in response to metabolic stress (MCD diet) and display aggravated steatohepatitis in response to alcohol intake $[14,15]$. Finally, $\beta$-catenin is one of the most frequently mutated genes involved in malignant transformation and plays also a pivotal role in hepatic tumorigenesis [16]. Approximately $50 \%$ of patients suffering from hepatocellular carcinoma (HCC), up to $90 \%$ with hepatoblastoma (HB), and also patients with benign hepatoadenoma (HA) display mutations in the $\mathrm{Wnt} / \beta$-catenin pathway $[17,18]$. The vast majority of patients carry mutations located in exon 3 of the CTNNB1 gene, resulting in a degradation resistant form of $\beta$-catenin [19]. These missense mutations in exon 3 of CTNNB1 represent a subgroup of liver cancer with distinctive clinical and pathological features [20]. We recently presented a novel mouse model characterized by hepatocyte specific loss of exon 3 of Ctnnbl (Ctnnbl ${ }^{C A}$ hep mice and $C t n n b 1^{T C C A}$ hep mice). The resulting truncated version of $\beta$-catenin is fully functional but resistant to degradation. Using this model we demonstrated that continuous expression of $\beta$-catenin in hepatocytes induces cholestasis and a biliary type of fibrosis [21]. Following up on our previous study, here we analyzed the consequences of continuous $\beta$-catenin signaling on survival of $C t n n b 1^{C A}$ hep mice and observed major metabolic defects leading to premature death and mitochondrial dysfunction.

\section{RESULTS}

\section{Continuous $\beta$-catenin signaling in hepatocytes leads to premature death in mice}

In our previous work we showed that $C t n n b 1^{C A}$ hep mice, expressing a degradation resistant form of $\beta$-catenin, displayed severe deregulation of hepatic, renal and ileal transporters and disturbed liver architecture lacking lobule formation at weaning age [21]. To assess the long-term consequences of $\beta$-catenin expression we performed Kaplan Meier survival statistics (Figure 1A). All Ctnnb $1^{\text {CA hep }}$ mice died within 31 days after birth with a median survival time of 25 days. Ctnnb1 $1^{\text {CA hep }}$ mice were smaller and their body weight was significantly reduced compared to their Crenegative littermates ( $8.05 \mathrm{~g}$ vs. $9.22 \mathrm{~g}$; Figure 1B). Livers of $C t n n b 1^{\text {CA hep }}$ mice were significantly enlarged $(0.92 \mathrm{~g}$ vs. $0.41 \mathrm{~g}$; Figure 1C) resulting in an increased liver to body weight ratio (11.5\% vs. $4.5 \%$; Figure 1D).

\section{Permanent active $\beta$-catenin leads to severe deregulation of protein homeostasis in livers}

In order to study the lethal phenotype of constitutive $\beta$-catenin signaling in hepatocytes in more detail, we performed whole liver proteomic analyses. Overall, 3853 individual proteins were identified by mass spectrometry analysis in livers of Ctnnb1 $1^{C A}$ hep and control mice, of which 3159 were unaltered and 694 proteins $(21.9 \%)$ were significantly deregulated in $C$ tnnb $1^{C A}$ hep mice compared to WT littermates, respectively ( $p$-value $<0.05 ; 0.58$ $\log 2$ fold change in expression; Supplementary Table 1). From those, 343 proteins were up-regulated and 351 proteins were down-regulated in livers of $C t n n b 1^{\text {CA hep }}$ mice compared to WT littermates. (Figure 2A).

In order to understand the biological relevance of the deregulated proteins we performed Ingenuity ${ }^{\mathbb{B}}$ Pathway Analysis (IPA), which revealed that up-regulated proteins were involved in canonical pathways including the superpathway of cholesterol biosynthesis, PXR/ RXR function and estrogen biosynthesis (Figure 2B). Analyzing the significantly down-regulated proteins, the top deregulated canonical pathways identified were mitochondrial dysfunction, oxidative phosphorylation, tryptophan degradation and the urea cycle (Figure 2C).

Moreover, up-regulated proteins were associated with molecular functions related to different metabolic processes (lipids, nucleic acids, amino acids) and energy production (Figure 2D). Analysis of down-regulated proteins identified proteins involved in metabolic functions (lipids, vitamins and minerals, drugs), for energy production and carbohydrate metabolism (Figure 2D). When analyzed for liver toxicity we identified a strong association of the deregulated proteins with liver steatosis, liver cholestasis and hyperplasia/carcinoma for up- and down regulated proteins, respectively (Figure 2E). 
Together, these data suggest that aberrant hepatic $\beta$-catenin signaling largely affects proteins involved in essential metabolic and energy production pathways in the liver.

\section{Mice expressing constitutively active $\beta$-catenin in hepatocytes suffer from severe disturbances in lipid metabolism}

Macroscopically, livers of Ctnnb1 $^{\text {CA hep }}$ mice had a yellowish and swollen appearance indicating steatosis (Figure 3A). This was confirmed by toluidine blue staining, highlighting severe hepatocellular fat accumulation in Ctnnbl $^{\text {CA hep }}$ mice (Figure 3B). Lipid droplets were predominantly observed in hepatocytes surrounding central veins (zone III of liver lobules) as revealed by $\mathrm{H} \& \mathrm{E}$ stained sections from livers of $C t n n b 1^{C A}$ hep mice (Figure 3C). Further, livers of Ctnnb1 ${ }^{\text {CA hep }}$ mice displayed increased triglyceride content (29.5 vs. $22.9 \mu \mathrm{g}$ triglyceride/mg liver; Figure 3D). Serum cholesterol levels were also significantly elevated compared to WT animals (128.2 vs. 93.8 mg/dL; Figure 3E). Moreover, HDL levels were significantly increased in $C$ tnnb1 ${ }^{\text {CA hep }}$ mice (120.8 vs. $77.1 \mathrm{mg} / \mathrm{dL}$; Figure $3 \mathrm{~F}$ ), suggesting reverse cholesterol transport from peripheral white adipose tissue (WAT) to the liver. Interestingly, there was a decrease of non-HDL cholesterol levels in the serum of Ctnnb1 ${ }^{\text {CA hep }}$ mice (18.8 vs. $28.2 \mathrm{mg} / \mathrm{dL}$; Figure $3 \mathrm{G}$ ). No changes with regards to free fatty acid (FA) levels were observed (Supplementary Figure 1A).

\section{Key enzymes involved in synthesis and transport of FA and cholesterol were significantly deregulated in livers of Ctnnb1 $1^{\text {CA hep }}$ mice}

To investigate the steatosis phenotype of $C \operatorname{tnnb1}{ }^{C A}$ hep mice in more detail we performed gene expression analysis of key genes involved in lipid metabolism. The mRNA expression of fatty acid synthase (Fasn; 1.1 vs. 1.0 fold expression; Figure 4A) was not significantly deregulated in $C t n n b 1^{C A}$ hep mice compared to WT littermates. Interestingly, we detected significantly higher levels of FASN protein in Ctnnb1 ${ }^{\text {CA hep }}$ mice based on our proteomics analyses, suggesting a posttranscriptional regulation of FASN. In contrast, mRNA levels of the main transporter for FA in the liver Fabpl (0.33 vs. 1.00 fold expression; Figure 4B) and the alternative transporter Fabp5 (0.57 vs. 1.0 fold expression; Figure 4C) were significantly reduced. FABP5 was also significantly reduced on protein level (Supplementary Table 2A),

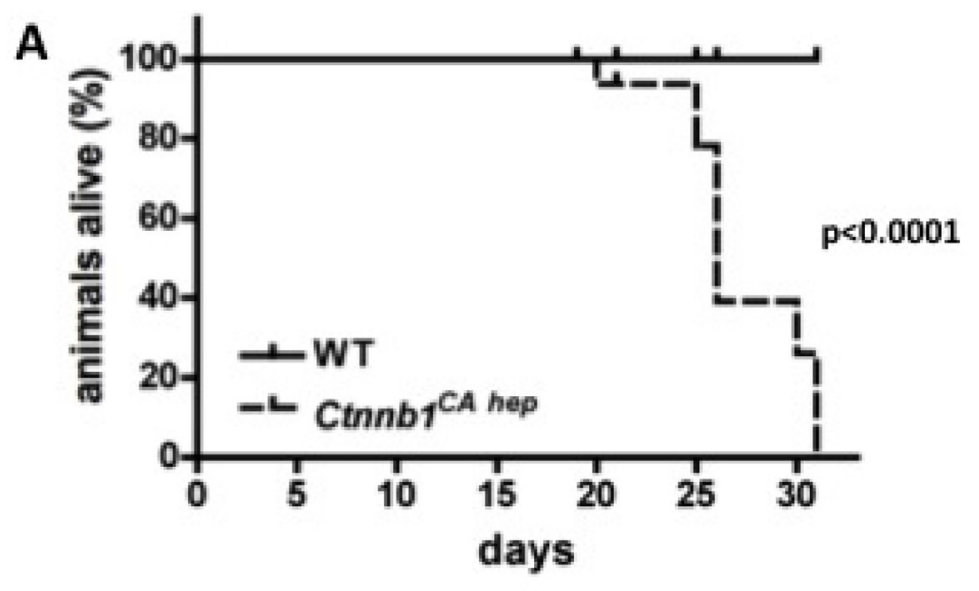

B

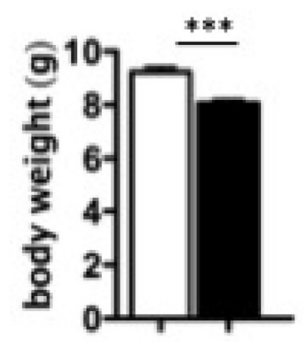

C

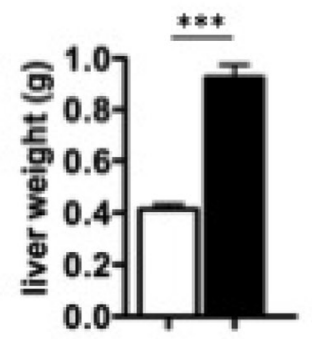

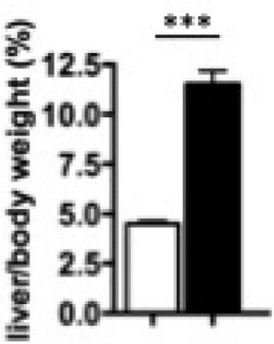

WT controls Ctnnb1 ${ }^{\text {CA hep }}$

Figure 1: Continuous $\boldsymbol{\beta}$-catenin signaling in hepatocytes results in $\mathbf{1 0 0} \%$ mortality and hepatomegaly. All $C t n n b 1^{C A}$ hep mice die within 31 days post partum, whereas WT animals display no mortality as shown by Kaplan Meier survival analysis $(n=15)(\mathbf{A})$. Ctnnb1 ${ }^{C A}$ hep mice have significantly reduced body weight (B) but significantly enlarged livers (C) resulting in a highly increased liver/body weight ratio (D). 
while no significant changes were observed for FABP1 (Supplementary Table 1). These proteins facilitate the transport of lipophilic substances from outer cell membranes of hepatocytes to inner ones, and might be regulated by a negative feedback mechanism. These data suggest that a down-regulation of transporters may protect

A
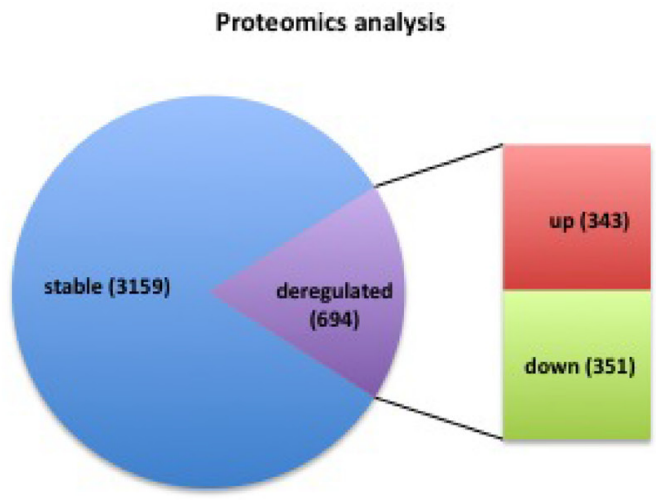

B

Canonical Pathways affected by up-regulated proteins

= up \% no change \%

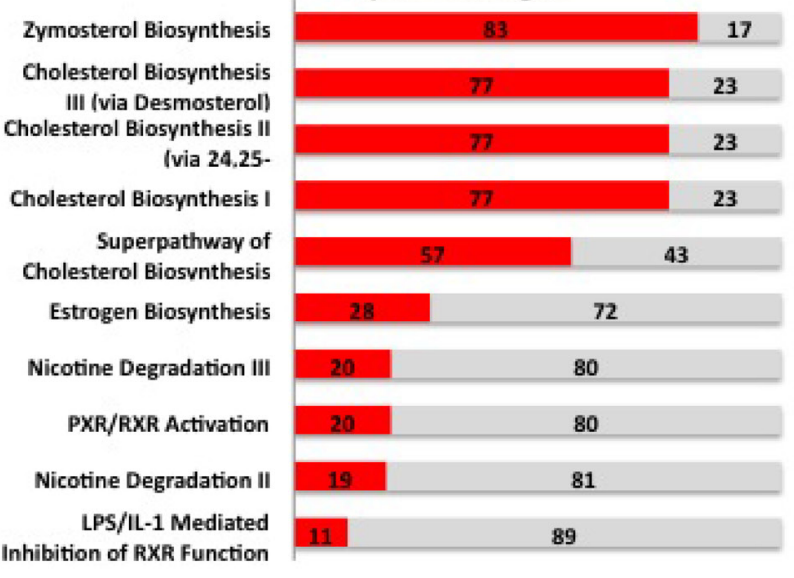

\section{3}

3 the liver from an overload of continuously provided lipids transported from the periphery in order to limit the aggravation of steatosis.

In line with these results, mRNA levels of microsomal triglyceride transfer protein large subunit, which plays a central role in lipoprotein assembly and

\section{c}

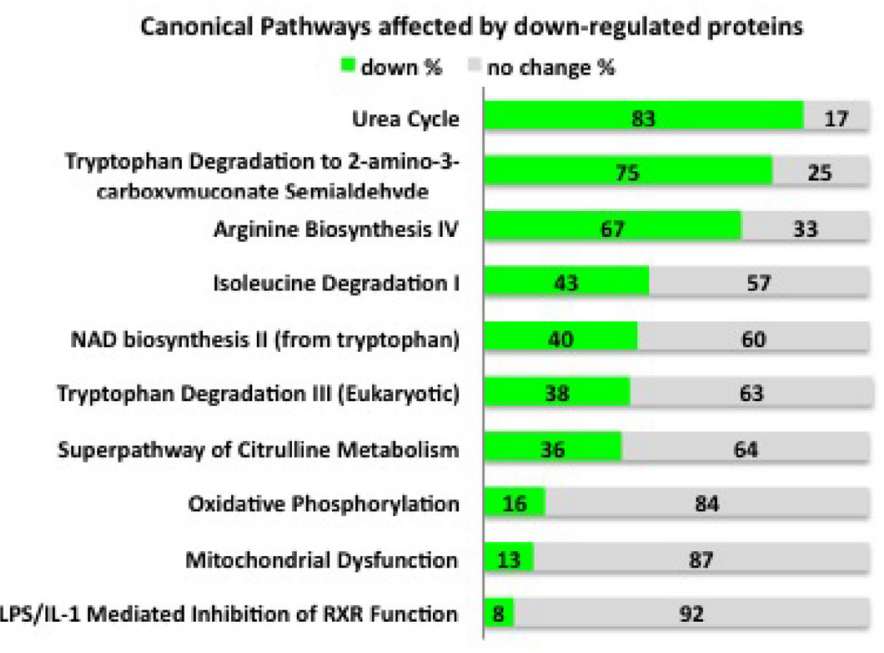

D

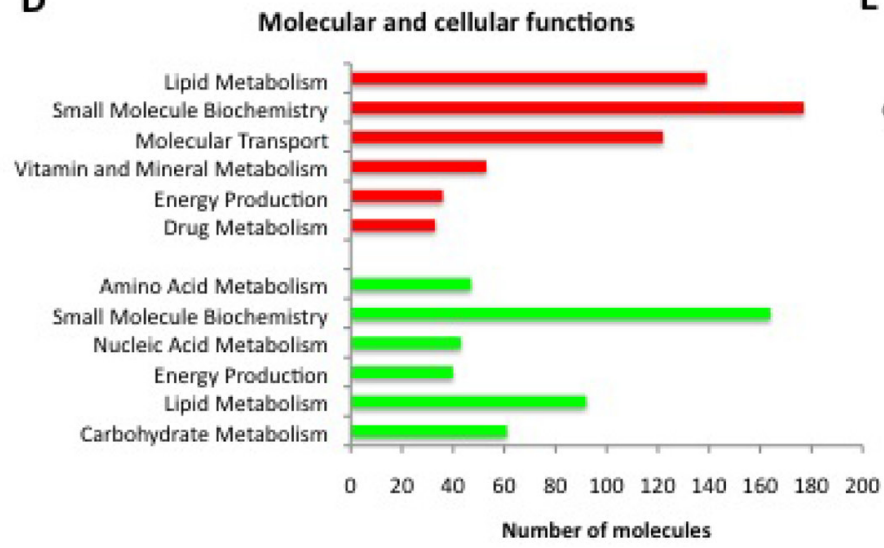

E

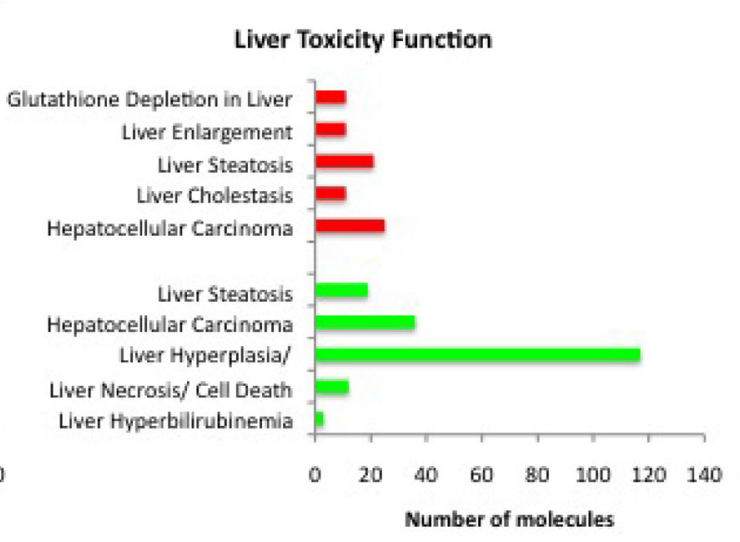

Figure 2: $\boldsymbol{C t n n b 1}^{\text {CA hep }}$ mice have severe disturbances in protein composition. (A) Proteomics analysis identifies a total of 3863 proteins of which 3159 are expressed to a similar extend and 694 proteins are significantly deregulated in Ctnnb1 ${ }^{\text {CA hep }}$ mice compared to WT littermates, $(21.9 \%, p$-value $<0.05 ; 0.58 \log 2$ fold change in expression). 343 proteins are up-regulated and 351 proteins down-regulated. Ingenuity ${ }^{\mathbb{B}}$ Pathway Analysis revealed top deregulated canonical pathways in $C t n n b 1^{C A}{ }^{C h e}$ mice compared to WT littermates $(\mathbf{B}, \mathbf{C})$. Deregulated proteins were analyzed according to their function and clustered into groups for molecular function (D) and liver toxicity (E). 
hepatocellular excretion of lipids, were decreased in Ctnnb1 ${ }^{\text {CA hep }}$ mice (Mttp; 0.6 vs. 1.0 fold expression; Figure 4D). Moreover, key regulators of de novo lipogenesis, sterol regulatory element-binding protein 1c (Srebp1c; 0.27 vs. 1.0 fold expression; Figure 4E) and stearoyl-CoA desaturase ( $S c d 1 ; 0.27$ vs. 1.0 fold expression; Figure 4F) were significantly reduced on mRNA levels, suggesting a compensatory reduction of lipid synthesis. These proteins were not detected in our proteomics analyses (Supplementary Table 1), however IPA analysis revealed an increase of proteins involved in the melanovate pathway. This pathway is responsible for syntheses of fatty acid from isoprenoid, which are further used in cholesterol generation and finally bile acid synthesis (Supplementary Table 2C).

$\mathrm{Wnt} / \beta$-catenin signaling has been shown to maintain pre-adipocytes in an undifferentiated state through inhibition of the adipogenic transcription factors CCAAT/ enhancer binding protein alpha $(C / e b p \alpha)$ and peroxisome proliferator-activated receptor gamma (Ppar $\gamma)$ [22]. In this respect, mRNA levels of C/ebp $\alpha$ were significantly reduced in livers of $C$ tnnb1 ${ }^{C A}$ hep mice (0.48 vs. 1.0 fold expression; Figure 4G). No differences in mRNA levels of Ppary and Ppara between Ctnnb1 $1^{C A}$ hep mice and littermate controls were observed (Supplementary Figure 1B, 1C). In proteomic analysis these proteins were not detected.

\section{Mice expressing constitutively active $\beta$-catenin in hepatocytes suffer from severe disturbances in glucose metabolism}

Ctnnb1 ${ }^{\text {CA hep }}$ mice displayed rapid wasting, suggesting a deregulation of energy metabolism. Under baseline conditions blood glucose levels of Ctnnb1 ${ }^{C A}$ hep mice did not differ from littermate controls (Figure 5A). However, hepatocytes of $C t n n b 1^{C A}$ hep mice almost completely lacked
A
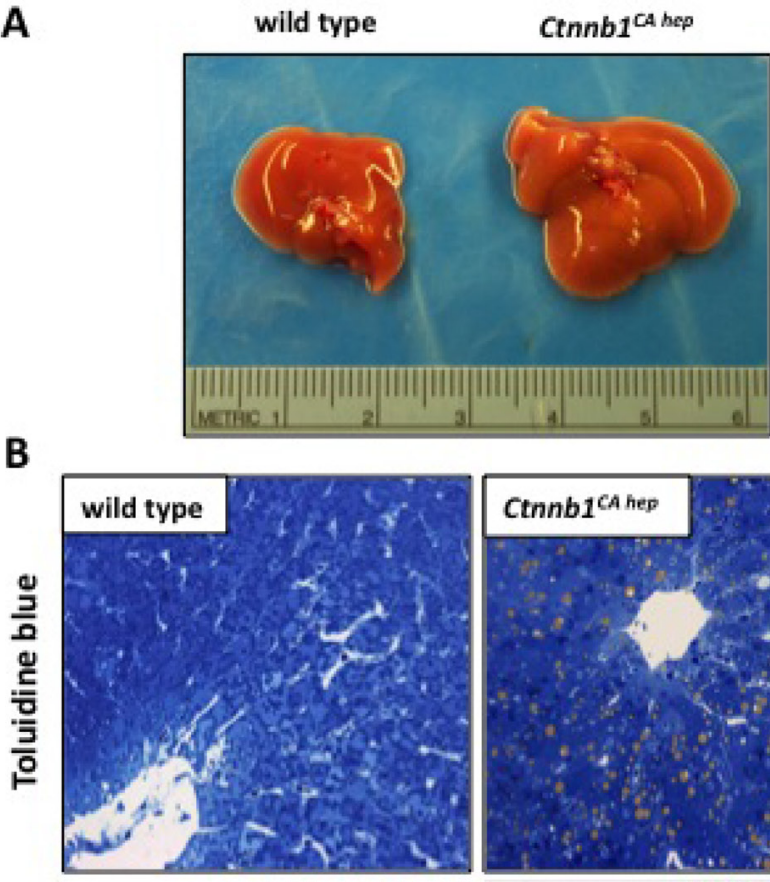

C

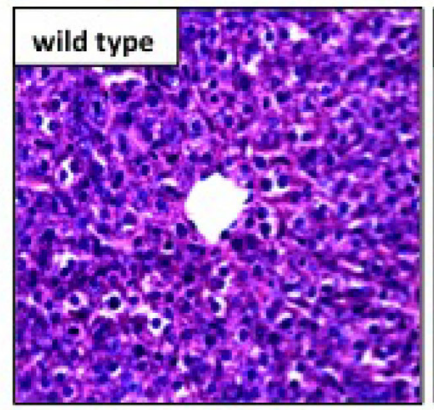

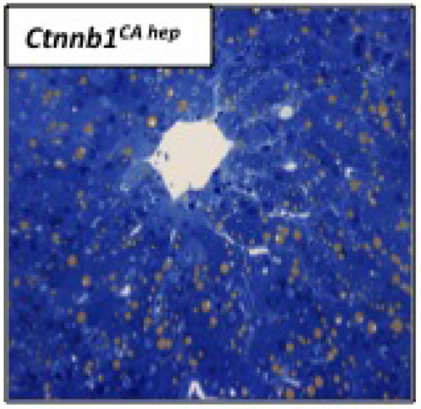

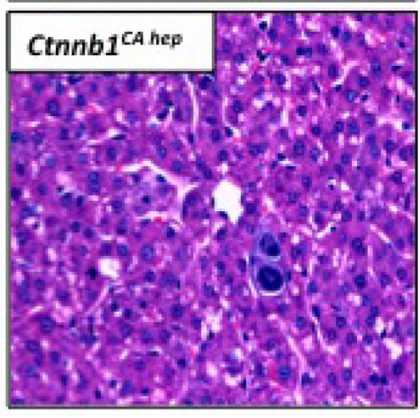

D

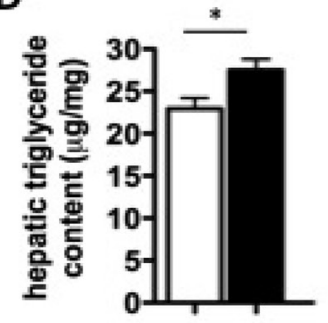

F

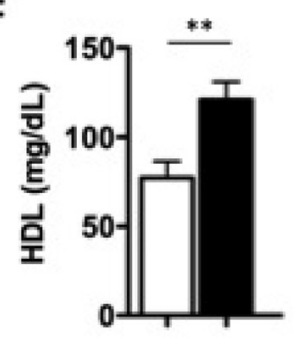

E

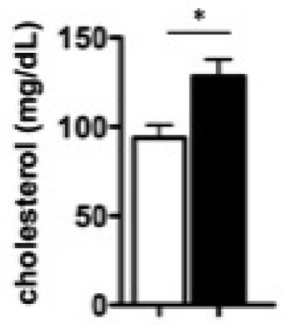

G
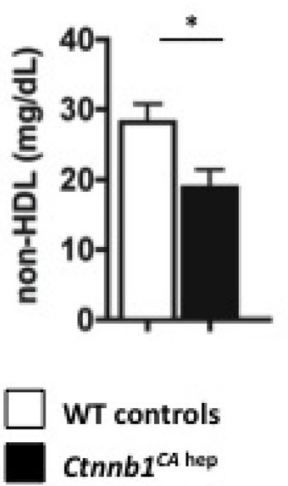

Figure 3: Ctnnb1 ${ }^{\text {CA hep }}$ mice display hepatic steatosis. Livers of Ctnnb1 $1^{\text {CA hep }}$ mice are enlarged and show a yellowish appearance compared to livers of WT littermates (A). Livers of Ctnnb1 $1^{C A}$ hep mice display hepatocellular fat accumulation around central veins confirmed by toluidine blue staining (B) and $\mathrm{H}$ and E staining (C). Livers are characterized by increased triglyceride content (D). Serum analysis showed significant increase of cholesterol and HDL cholesterol levels in Ctnnb1 ${ }^{C A}$ hep mice (E, F), however there was a decrease in non-HDL cholesterol (G). 
glycogen storage as demonstrated by periodic acid-Schiff (PAS) staining (Figure 5B). In line with this observation, mRNA levels of liver-specific phosphofructokinase (Pfkl), the rate-limiting enzyme in glycolysis, was down-regulated (Figure 5C). Liver specific glycogen phosphorylase ( $P y g l)$ and fructose 1,6-bisphosphatase ( $F b p 1)$, key and rate-limiting enzymes in glycogen degradation and gluconeogenesis, respectively, were also significantly reduced in livers of Ctnnb1 ${ }^{\text {CA hep }}$ mice (Figure 5D and 5E). Glycogen synthase (Gys2), the key enzyme in storage of glucose as glycogen, did not differ between $C_{\text {tnnbl }}{ }^{\text {CA hep }}$ mice and controls (Figure 5F). The deregulation of these key enzymes was also reflected in our proteomics data in addition to significant down-regulation of numerous enzymes involved in carbohydrate metabolism (Supplementary Table 2B).

Glucose and other carbohydrates are shuttled into the liver cells by the family of integral membrane glucose transporter (GLUT) molecules. The most abundant transporter in the liver is GLUT2 (solute carrier transporter family 2 member a2 SLC2A2), which was down-regulated on protein level as confirmed by Western blot (Figure 5G) and proteomics analysis in Ctnnbl $1^{\text {CA hep }}$ mice (Supplementary Table 1). Western blot analysis of two other abundant glucose transporters GLUT1 and SCL5A1 revealed no changes between the phenotypes (data not shown). Together, these data suggest that the deregulation of proteins involved in carbohydrate breakdown resulted from a deficiency of their substrate glucose and glycogen in livers of $C t n n b 1^{\text {CA hep }}$ mice.
Interestingly, liver proteomics revealed an up-regulation of alternative energy pathways. In $C t n n b 1^{C A}$ hep mice enzymes involved in the Cahill cycle, which generates pyruvate from muscle-derived alanine, as well as the glutamine synthase cycle enzymes were highly up-regulated (Supplementary Table 2E). The increased use of muscle proteins for energy supply is associated with cachexia, reflected by the decreased body weight and feeble appearance of $C \operatorname{tnnb1}^{\mathrm{CA}}$ ${ }^{h e p}$ mice. Moreover, the key enzyme in lactate metabolism, L-lactate dehydrogenase subunit B (LDHB), which generates pyruvate from muscle derived lactate and was significantly up-regulated (Supplementary Table 2E). Increased lactate metabolism is a key mechanism of the cancer specific Warburg effect, which is characterized by glycolysis followed by lactate acid fermentation in the cytosol, rather than betaoxidation in mitochondria. Another remarkable observation was the up-regulation of rate limiting enzymes of glycolysis (hexokinase 2, phosphofructokinase, and pyruvate kinase; Supplementary Table 2B). This feature has been observed in different tumors, like colon, prostate and also liver cancer and is also an indication for anaerobe glycolysis in cancer cells $[23,24]$.

\section{Continuous $\beta$-catenin signaling leads to massive mitochondrial damage}

Proteomic analysis revealed a severe disturbance of mitochondrial protein homeostasis, and IPA pathways
A

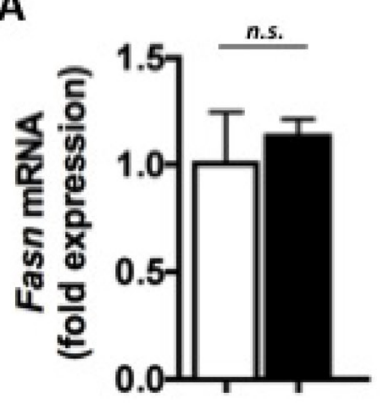

D

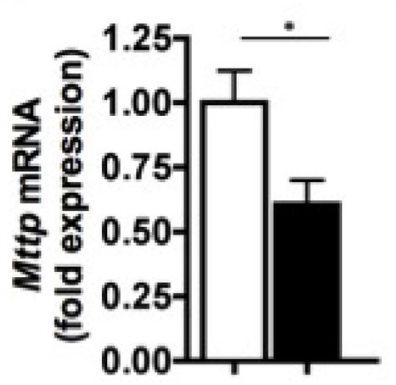

B

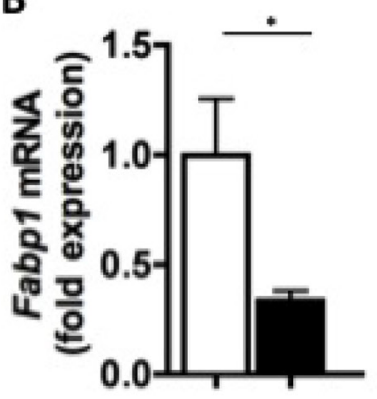

E

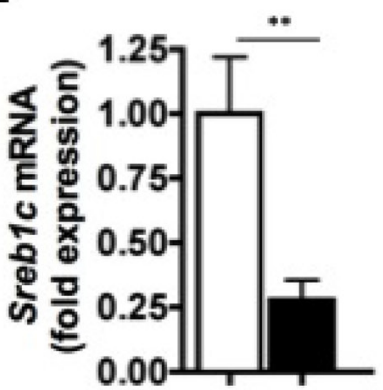

C

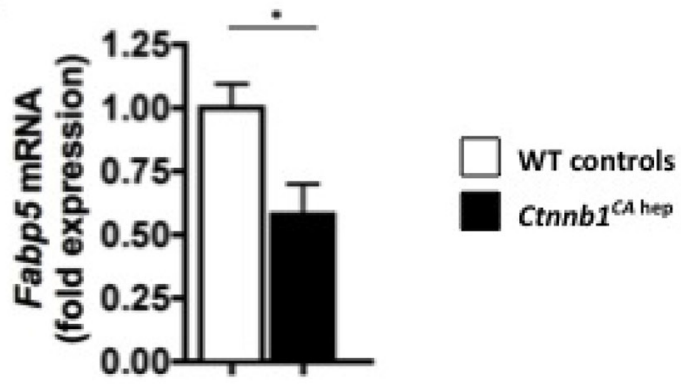

$\mathbf{F}$

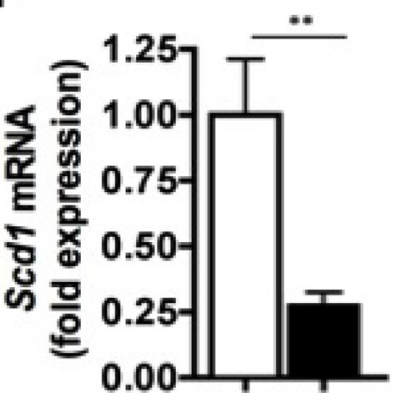

G

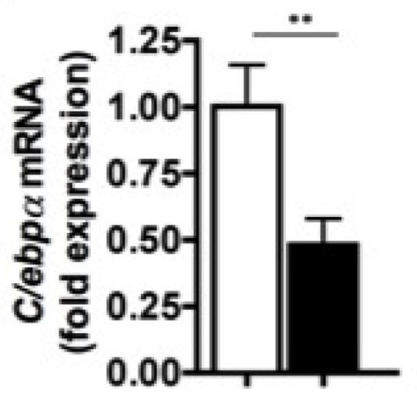

Figure 4: $\boldsymbol{C t n n b 1}^{\text {CA hep }}$ mice display deregulation of key enzymes of lipid metabolism. Fatty acid synthase (Fasn; A), fatty acid binding proteins $1(\mathrm{Fabpl}$; B) and $5(\mathrm{Fabp} 5 ; \mathbf{C})$ microsomal triglyceride transfer protein large subunit $(\mathrm{Mttp}$; D), sterol regulatory element binding protein $1 \mathrm{c}(\mathrm{Sreb} 1 \mathrm{c} ; \mathbf{E})$ and stearoyl-CoA desaturase $(\mathrm{Scd} 1 ; \mathbf{F})$ as well as adipogenic transcription factor CCAAT/enhancer binding protein alpha $(\mathrm{Clebp} \alpha, \mathbf{G})$ were down-regulated on mRNA level in $C_{t n n b 1}{ }^{\text {CA hep }}$ mice. 
analysis predicted mitochondrial dysfunction based on deregulation of proteins associated with mitochondrial function (Figure 2C). A high number of enzymes involved in beta-oxidation and in the respiratory chain, the most important pathways to generate ATP and therefore energy, were significantly down-regulated in Ctnnb1 $1^{\text {CA hep }}$ mice (Supplementary Table 2C). Additionally, proteins of the citrate-cycle, responsible for the energy-producing break down of metabolites from carbohydrate, lipid and protein metabolism, were also massively reduced (Supplementary Table 2C). Moreover livers of Ctnnb1 ${ }^{\text {CA hep }}$ mice displayed deregulation of molecules involved in oxidative as well as ER stress responses. Glutathione reductase, glutathione S-transferase and paraoxonase 1 were up-regulated, while glutathione reductases were down-regulated (Supplementary Table 2C).

Electron microscopy demonstrated that hepatic mitochondria of Ctnnb1 $1^{\text {CA hep }}$ mice indeed had a pathologic phenotype (Figure 6A, 6B). They were swollen with rounded shape and displayed reduced matrix density compared to mitochondria of WT controls. This phenotype was more severe around central veins than in periportal areas. The number of mitochondria per hepatocyte was slightly decreased in Ctnnb1 ${ }^{\text {CA hep }}$ mice compared to WT controls (Figure 6C). However the area occupied by mitochondria was larger in $C t n n b 1^{\text {CA hep }}$ mice, which might be due to matrix swelling (Figure 6D).
A

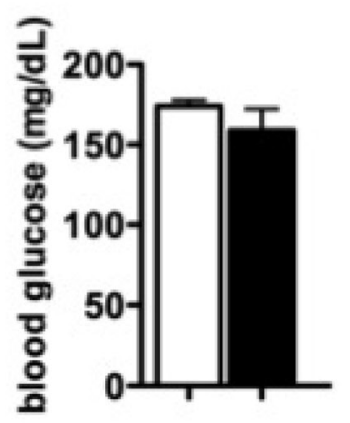

C

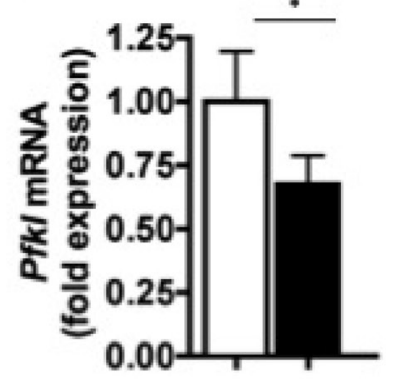

B

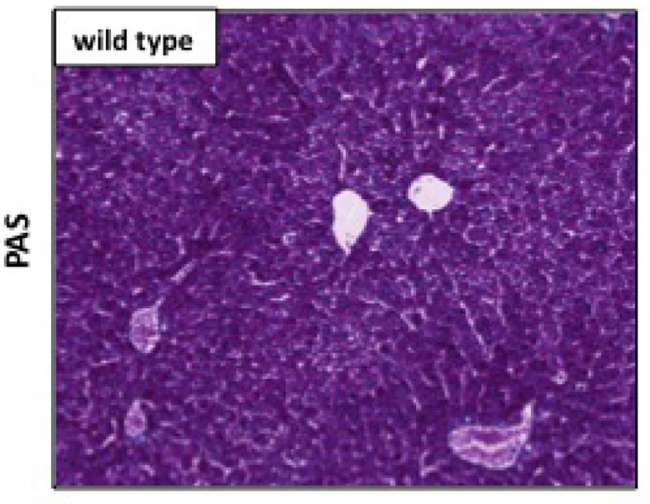

D

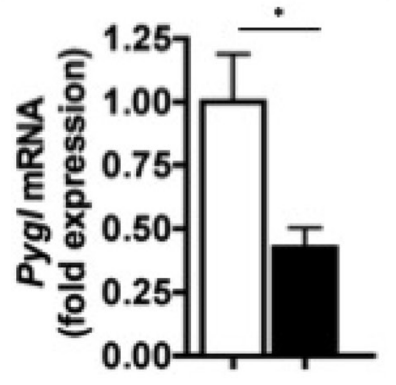

E

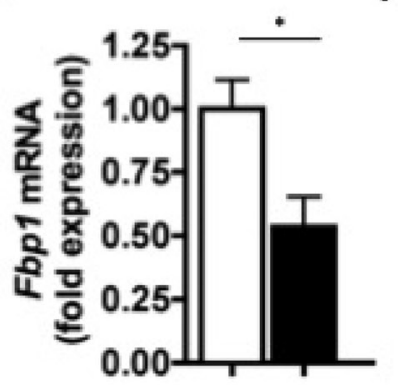

F

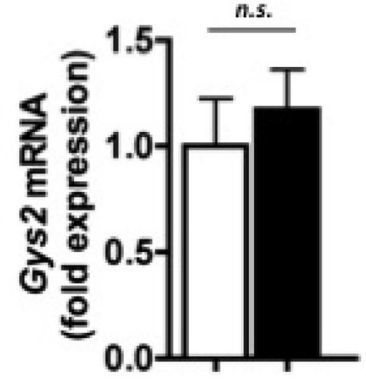

G
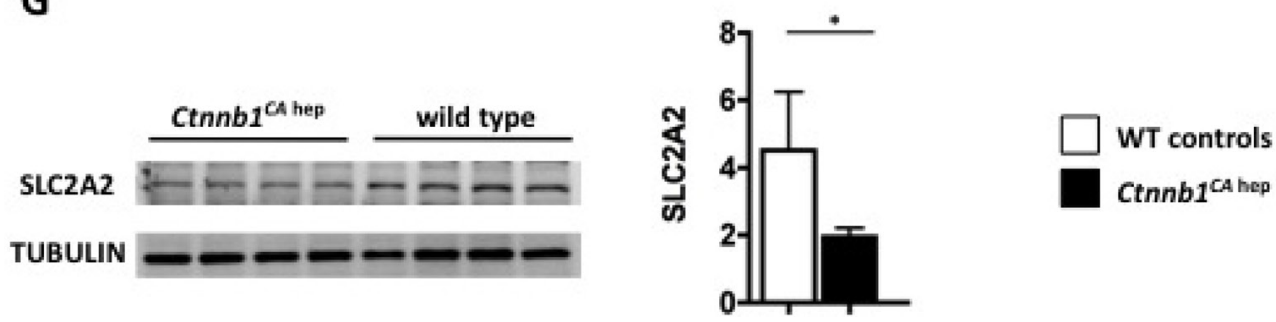

Figure 5: Ctnnb1 ${ }^{\text {CA hep }}$ mice display severe disturbances in carbohydrate metabolism. No difference in blood glucose levels between $C t n n b 1^{C A h e p}$ and WT littermates was detectable (A). PAS staining shows severely decreased levels of glycogen in $C t n n b 1^{C A h e p}$ mice (B). mRNA levels of key enzymes in glucose metabolism including Phosphofructokinase (Pfkl, C), liver specific glycogen phosphorylase (Pygl, D) and fructose 1,6-bisphosphatase (Fbp1, E) were significantly down-regulated in livers of Ctnnb1 ${ }^{\text {CA hep }}$ mice. Glycogen synthase 2 (Gys2, F) was not deregulated on mRNA level. Western blot analysis revealed down-regulation of main glucose transporter GLUT2 (SLC2A2) in livers of Ctnnb1 $1^{\text {CA hep }}$ mice compared to WT controls (G). 
Beside mitochondria, beta-oxidation can also take place in peroxisomes. Indeed, levels of peroxisomal proteins were highly increased in $C t n n b 1^{C A}$ hep mice, indicating an increase of peroxisomal activity (Supplementary Table 2D). Moreover, electron microscopy revealed that peroxisomes of $C t n n b 1^{C A}$ hep mice are highly enlarged but not increased in number (Figure 6B, 6E). Together, these data suggest that the massive deregulation of metabolic homeostasis in $C t n n b 1^{C A}$ hep mice results in pathological alterations of mitochondria and peroxisomes.

\section{Mice expressing constitutively active $\beta$-catenin in hepatocytes do not tolerate fasting}

To further investigate the metabolic conditions of Ctnnb1 ${ }^{\text {CA hep }}$ mice we performed fasting experiments. After weaning at the age of 21 days, food was withdrawn from Ctnnb1 $1^{\text {CA hep }}$ mice and wild type controls. After 6 hours, the experiment had to be terminated as Ctnnb1 ${ }^{C A}$ hep mice became lethargic and showed a weak constitution. After the fasting period, Ctnnb1 $1^{\text {CA hep }}$ mice did not show a change in overall body weight (Figure 7A). However, livers of fasted $C t n n b 1^{\text {CA hep }}$ mice appeared yellowish and spongy (Figure 7B) and were significantly heavier compared to un-fasted Ctnnb1 ${ }^{\text {CA hep }}$ mice and WT littermates (1.29 vs. 0.92 vs. 0.44 g, Figure $7 \mathrm{C}$ ) resulting in an even more pronounced liver to body weight ratio than in fed animals (13.0 vs. 11.5 vs. 4.5, Figure 7D). The visceral fat pad was significantly reduced in $C t n n b 1^{C A}$ hep mice (0.02 vs. $0.08 \mathrm{~g}$, Figure 7E). After 6 hours of fasting Ctnnb1 ${ }^{C A}$ hep mice displayed significantly reduced serum glucose levels compared to fed Ctnnb1 $1^{\text {CA hep }}$ mice and their WT littermates (116.2 vs. 142.2 vs. 164.6 mg/dL, Figure 7F). PAS staining revealed a complete lack of glycogen and additionally highlighted the severe hepatocellular steatosis around central veins in fasted Ctnnb1 ${ }^{C A}$ hep mice (Figure 7G). Despite the accelerated hepatic lipid accumulation of fasted $C t n n b 1^{C A}$ hep mice compared to unfasted mice, they displayed a reduction of Fasn $(0.55$ vs. 1.00 fold expression, Figure 8A), Fabpl (0.42 vs. 1.03 fold expression, Figure 8B), Fabp5 (0.36 vs. 1.00 fold expression, Figure 8C). However the mRNA levels of Mttp (0.38 vs. 1.0 fold expression; Figure 8D), Srebp 1c (0.05 vs. 0.99 fold expression; Figure $8 \mathrm{E}$ ), $S c d 1$ (0.23 vs. 0.99 fold expression; Figure 8F) and C/ebpa (0.12 vs. 1.0 fold expression; Figure $8 \mathrm{G}$ ) were even stronger reduced in fasted compared to unfasted Ctnnb1 ${ }^{C A}$ hep mice compared to their wild type controls.

\section{The metabolic phenotype is inducible in Ctnnb1 ${ }^{\text {TCCA hep }}$ mice}

To investigate if the deregulation of metabolic pathways results from a developmental defect of Ctnnb1 deletion, we also investigated inducible Ctnnb1 ${ }^{T C C A}$ hep mice, where continuous $\beta$-catenin signaling is induced by tamoxifen injection. Ten-week-old Ctnnb1 ${ }^{\text {TCCA hep }}$ mice and their healthy littermates were treated with tamoxifen as described before and analyzed 14 days after the first administration [25]. Ctnnb1 $1^{\text {TCCA hep }}$ mice displayed normal body weight (26.0 g vs. 25.9 g; Figure 9A) compared to their healthy littermates, however their livers were highly enlarged (2.6 g vs. $1.4 \mathrm{~g}$; Figure $9 \mathrm{~B}$ ) resulting in an impaired liver to body ratio ( $10.2 \%$ vs $5.6 \%$; Figure $9 \mathrm{C})$.

Similar to $C t n n b 1^{C A}$ hep mice, Ctnnb1 ${ }^{\text {TCCA hep }}$ mice also displayed a severe lack of glycogen, especially around portal fields as indicated by PAS staining (Figure 9D). In addition we also observed a mild steatosis around portal fields (Figure 9D), although no significant changes in hepatic triglycerides were detected $(57.0 \mathrm{vs} 70.0 \mu \mathrm{g}$ triglyceride/mg liver; Figure 9E). Serum analysis revealed significantly reduced blood cholesterol levels (18.5 vs. $54.0 \mathrm{mg} / \mathrm{dL}$; Figure 9F).

Moreover, qPCR analysis of key enzymes involved in lipid metabolism displayed a similarly decreased mRNA expression pattern as observed in the conditional $C t n n b 1^{C A}$ hep mice: Fasn (0.92 vs. 1.00 fold expression, Figure 10A), Fabpl (0.01 vs. 1.02 fold expression, Figure 10B), Fabp5 (0.15 vs. 1.00 fold expression, Figure 10C), Mttp (0.47 vs. 1.0 fold expression; Figure 10D), Srebplc (0.64 vs. 0.99 fold expression; Figure 10E), $S c d 1$ (0.09 vs. 1.00 fold expression; Figure 10F) and C/ebp $\alpha$ (0.45 vs. 1.00 fold expression; Figure 10G).

This data indicate that the early lethal phenotype observed in conditional Ctnnb1 $1^{C A}$ hep mice is not due to perturbation of hepatic development, but rather can be induced in adult mice by constitutional expression of $\beta$-catenin, highlighting the vital role of $\beta$-catenin in liver homeostasis and function.

\section{DISCUSSION}

Approximately $50 \%$ of patients with HCC display mutations in the $\mathrm{Wnt} / \beta$-catenin signaling pathway [20]. Recently, it was demonstrated that HCCs harboring somatic missense mutations in exon 3 of CTNNB1 represent a subgroup of liver cancer with distinctive clinical and pathological features [26, 27]. Here we show that hepatocyte specific expression of exon 3 mutated $C t n n b 1$ in mice (Ctnnb1 ${ }^{C A}$ hep $)$ resulted in a lethal phenotype with a median survival of 25 days after birth. At this time point not a single mouse had developed a lesion or tumor nodule. However, Ctnnb1 ${ }^{\text {CA hep }}$ mice displayed a severe phenotype characterized by disturbed liver architecture, deregulation of transporters and bile acids as well as cholestasis and biliary type of fibrosis [25]. The most impressive symptom was the rapid wasting of $C t n n b 1^{C A}$ hep mice from day 14 until their premature death, suggesting that continuous $\beta$-catenin signaling had a severe impact on metabolism and energy balance. The liver is the central organ of glucose, lipid and protein metabolism and responsible for energy supply. Comparing 
the phenotype of $C t n n b 1^{C A}$ hep mice to human liver disease we find parallels, especially in patients with metabolic liver disorders resulting in HCC or HB. A recent study described two distinct metabolic phenotypes of fetal and embryonic liver cancer. Fetal HB is characterized by large deletions in $C T N N B 1$, which encompass exon 3 and parts of exon 4, whereas embryonal HB more frequently display point mutations in the exon3 region of CTNNB1 [27]. Our data partially overlap with both phenotypes, however there is more similarity to the fetal subtype of $\mathrm{HB}$, especially concerning the glucose deficiencies and increased hexokinase 2 expression. Moreover, there are different metabolic disease like Glycogen storage disease (GSD), a rare disease characterized by defects in different key enzymes involved in glucose/glycogen metabolism. Patients suffer from deregulation of lipid metabolism and fatty liver steatosis [28]. The liver cancer incidence in these patients is high, although the pathogenesis of tumor formation is not understood [29]. However, 28\% of all GSD patients diagnosed with hepatocellular adenoma display mutations in $C T N N B 1$, which accelerate the metabolic phenotype and the malignant transformation towards HCC [30]. Also in Ctnnb1 ${ }^{C A}$ hep mice one of the fundamental metabolic problems is associated with lack of glucose/glycogen in the liver; the reasons therefore could be numerous. In our previous work we showed significant reduction of Fxr expression on mRNA as well as on protein level in $C t n n b 1^{C A}$ hep mice. It has been demonstrated that Fxr KO mice also suffer from severe disturbances in glucose metabolism due to the development of insulin resistance [31]. However, we can exclude insulinresistance in $C$ tnnb1 ${ }^{\text {CA hep }}$ mice since we did not observe differences in blood glucose concentration of either genotype, although enzymes involved in gluconeogenesis were also down-regulated.

In general continuous expression of the truncated form of $\beta$-catenin could lead to an over expression of target genes but also to a loss of interaction with specific co-activators of Wnt-target genes resulting in down regulation of target genes.

\section{A}

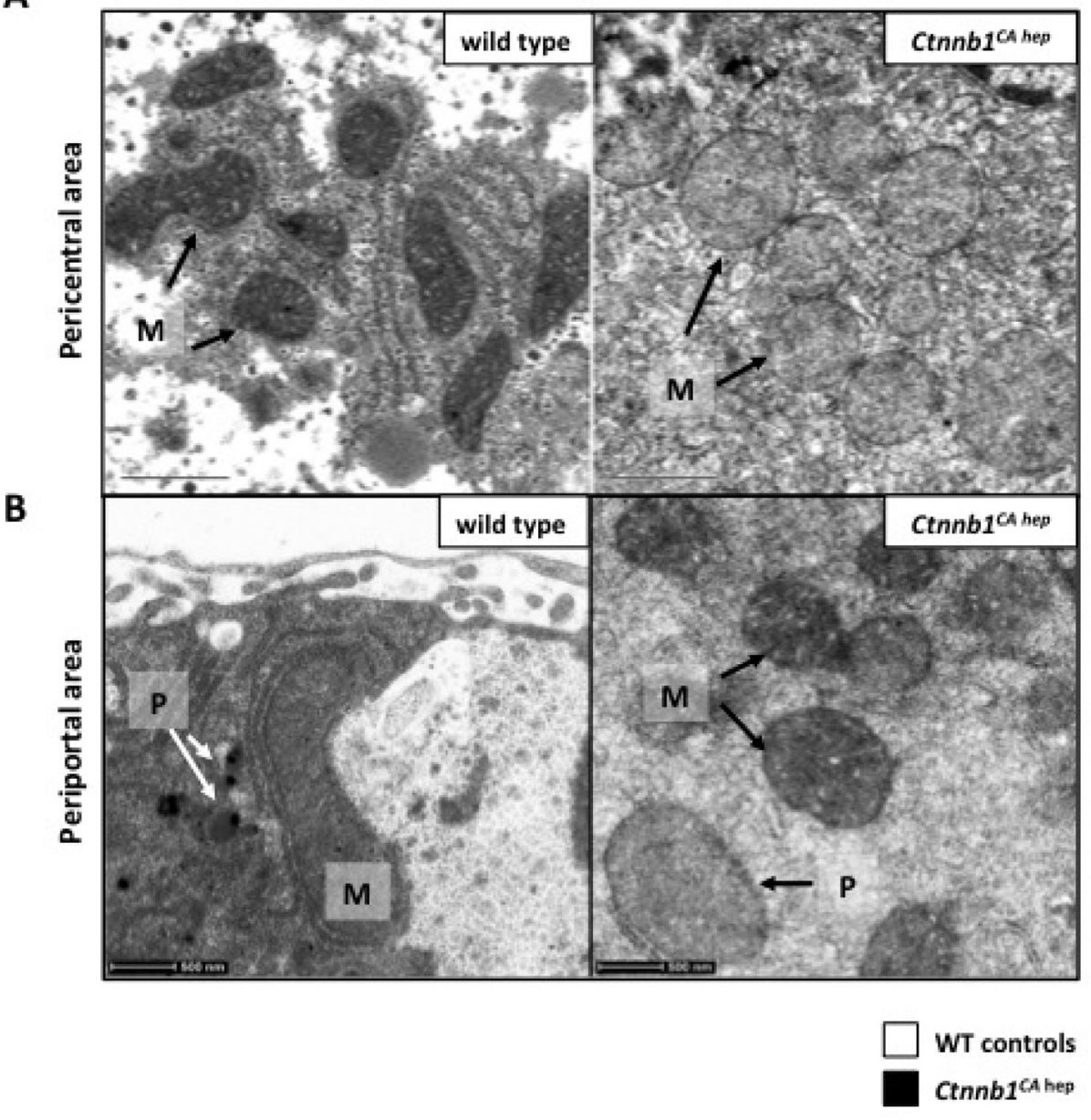

C

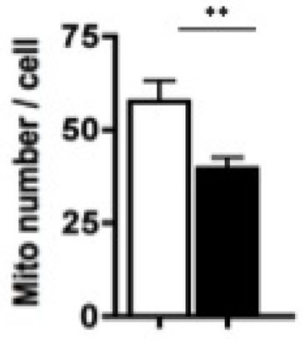

D

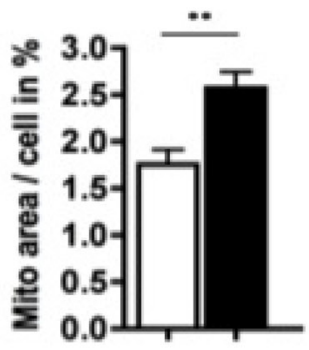

$\mathrm{E}$

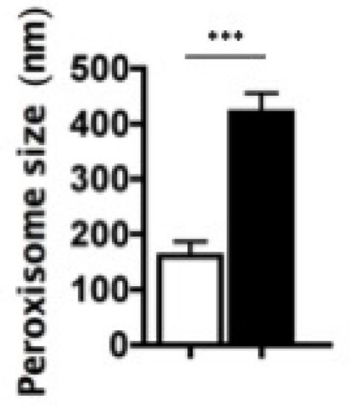

Figure 6: Ctnnb1 $^{\text {CA hep }}$ mice have a mitochondrial phenotype. Mitochondria (M) of Ctnnb1 ${ }^{\text {CA hep }}$ mice display a pathological phenotype shown by electron microscopic imaging. Especially around the central veins mitochondria are swollen with a rounded shape (A). Number of mitochondria per hepatocyte is decreased in $C t n n b 1^{C A}$ hep mice (B), however they occupy a larger area in the cell compared to WT animals (C). Peroxisoma (D) of Ctnnb1 ${ }^{C A}$ hep mice are highly enlarged and increased in number in $C t n n b 1^{C A h e p}$ mice $(\mathbf{B}, \mathbf{E})$. 
Most of the key enzymes responsible for glycolysis, glycogenesis and glycogenolysis were down-regulated on mRNA as well as on protein level suggesting a physiological regulation of enzymes due to the lack of their substrates glucose and glycogen. However, we cannot exclude down regulation due to defects on transcriptional level. Consequently, other substrates and pathways are needed to generate ATP.
An alternative way to maintain energy supply is the oxidation of free fatty acids in the mitochondria via betaoxidation and citric acid cycle and finally the respiratory chain. In Ctnnb1 ${ }^{C A}$ hep mice, especially in fasted animals, the increased fatty acid mobilization from the peripheral WAT seems to be an energetic rescue mechanism in order to perform beta-oxidation. According to the high intake and production of lipids, liver steatosis is observed in Ctnnb1 ${ }^{\text {CA hep }}$
A

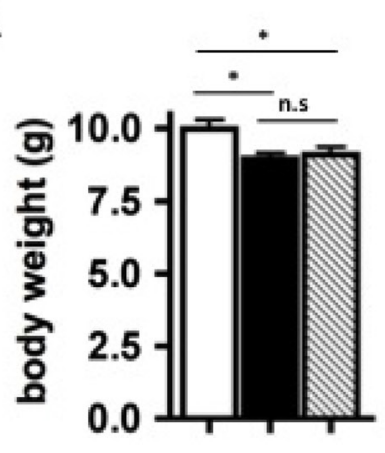

D

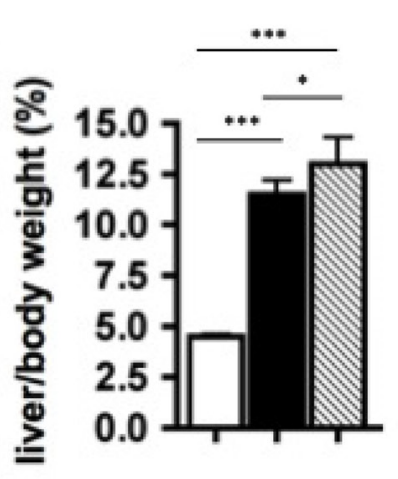

B

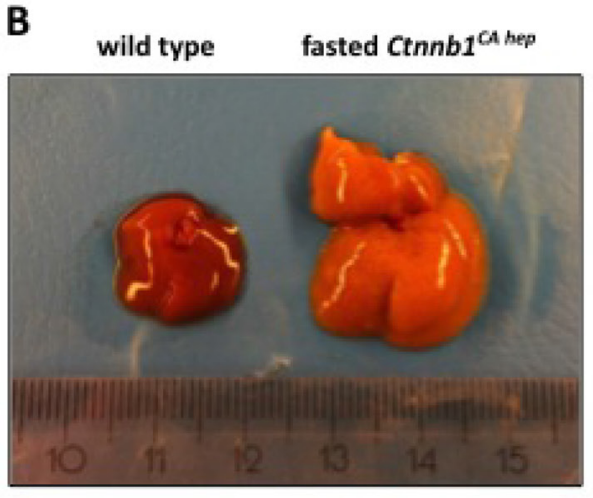

E

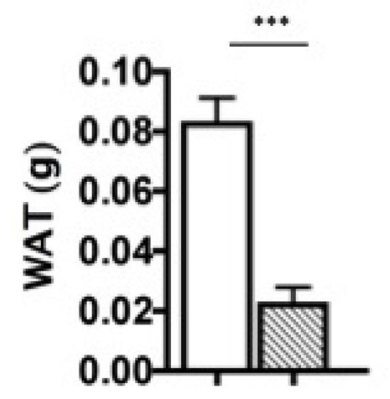

C

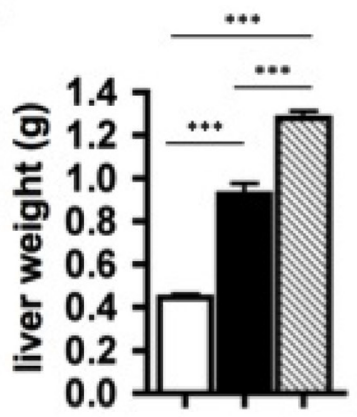

$\mathbf{F}$

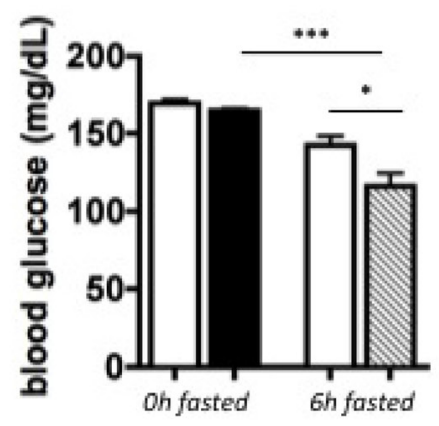

G
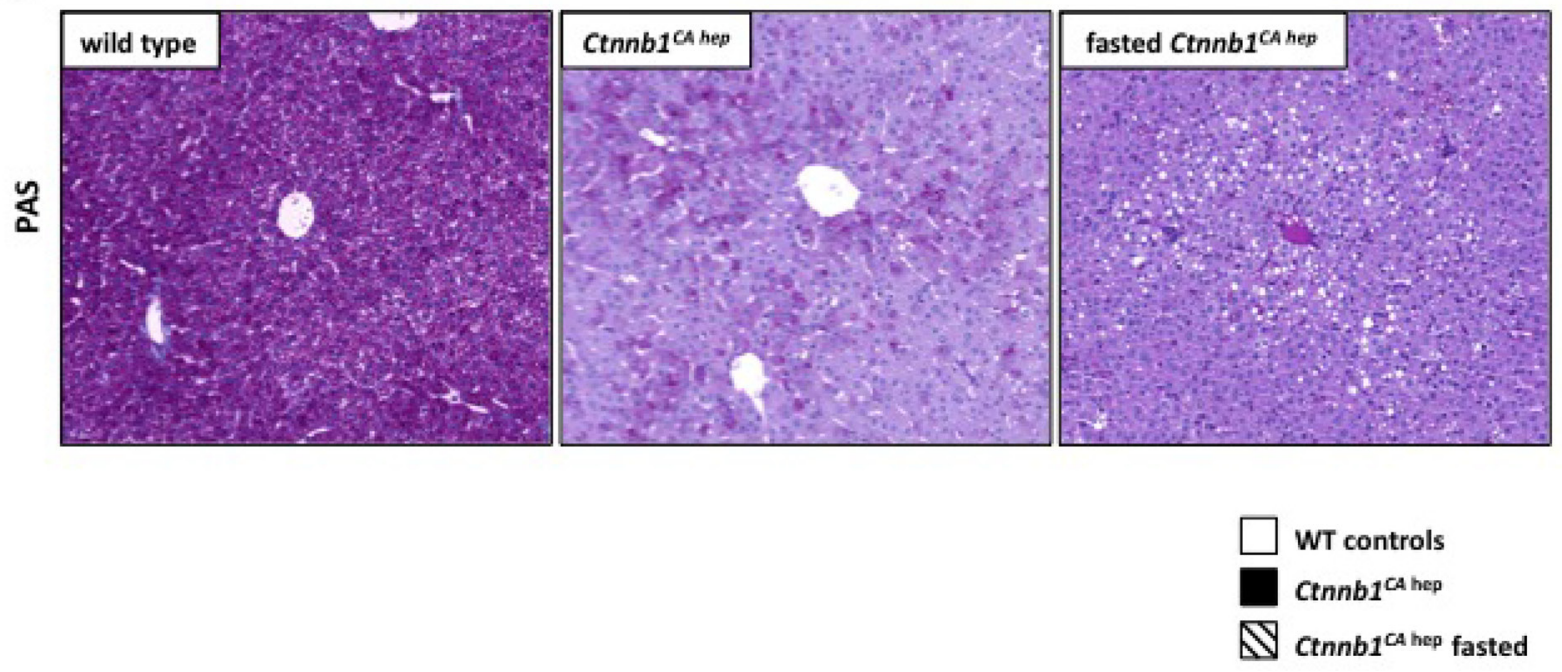

Figure 7: Fasting aggravates metabolic disturbances in $C_{t n n b} 1^{C A}$ hep mice. After 6 hours of fasting $C t n n b 1^{C A}$ hep mice showed no difference in body weight compared to normal fed Ctnnb1 ${ }^{C A}$ hep mice (A) but significantly enlarged livers (B, C) resulting in a significantly increased liver/body weight ratio (D). Fasted Ctnnb1 ${ }^{C A}$ hep showed reduced white adipose fat (WAT; E), reduced blood glucose levels (F) and the inability to form glycogen displayed by PAS staining $(\mathbf{G})$. 
mice, representing a typical feature of hepatic dysfunction. The decrease of key regulators of fatty acid transport on mRNA level seems to be a physiological response to prevent further accumulation of lipids in the liver. The release of lipids into the blood compartment combined with a decreased lipid clearance from the blood leads to hypercholesterolaemia and hypertriglyceridaemia similar to a human subgroup of patients suffering liver disease [32, 33]. In the liver two possible clearance strategies are observed; increase in bile acid synthesis to metabolize cholesterol and/or increased beta-oxidation, respectively. Indeed, $C t n n b 1^{C A}$ hep mice display increased levels of enzymes involved in the melanovate pathway, which is responsible for isoprenoid synthesis in order to generate cholesterol and steroids for bile acid synthesis. These findings suggest that the observed increase in bile acid synthesis, described in our previous work, is a rescue mechanism to clear the liver from lipids in order to prevent liver steatosis.

Beside mitochondria, also peroxisomes can perform beta-oxidation. Peroxisome activation and especially beta-oxidation comes in effect in conditions of substrate overload, facilitating clearance of especially long chain fatty acids. We therefore assume that the observed peroxisome phenotype is a reaction to the steatosis.

However, peroxisome beta-oxidation harbors the jeopardy of generating high levels of reactive oxygen species (ROS) and unlike mitochondria also hydrogen peroxide, which is converted to highly reactive hydroxyl radicals. Evidentially, significantly deregulated levels of enzymes involved in oxidative stress reaction were detected. These enzymes catalyze detoxification of lipidperoxides and ROS and are an indicator of oxidative injury of mitochondria. Moreover, levels of extracellular superoxide dismutase, another key mediator preventing oxidative damage were significantly down-regulated in Ctnnb1 ${ }^{\text {CA hep }}$ mice [34].

Finally, we suggest that the high levels of ROS and other peroxisomal derived radicals combined with the deregulation of oxidative stress response destroy mitochondria, especially around the central veins, where FA supply is the highest. Moreover, it has been shown that high activation of proto-oncogenes is able to induce downregulation of mitochondrial enzymes, which might be an additional problem in mice with continuous expression of $\beta$-catenin [35]. Interestingly, hepatocyte specific ablation of $\beta$-catenin also results in down-regulation of mitochondrial enzymes, highlighting its important role in maintenance of mitochondrial homeostasis [36].

Investigation of different mouse models overexpressing $\beta$-catenin display significant differences concerning the targeted effector molecule. Ctnnb1 ${ }^{\text {CA hep }}$ mice have a similar phenotype compared to hepatocyte specific Apc $\mathrm{KO}$ mice, which are also characterized by continuous $\beta$-catenin signaling. Apc $\mathrm{KO}$ mice also display an up-
A

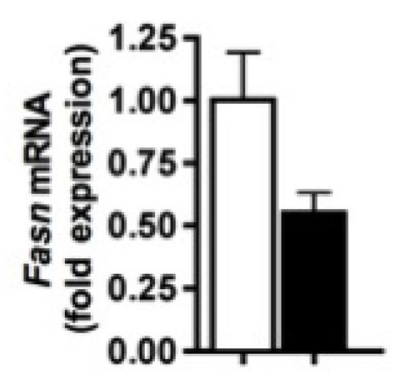

D

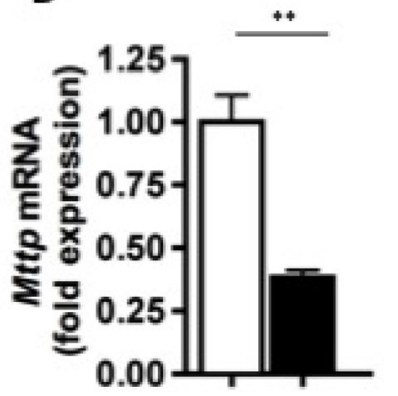

B

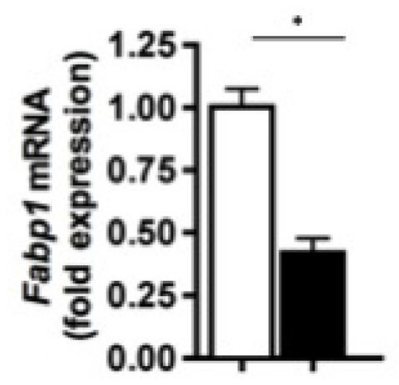

E

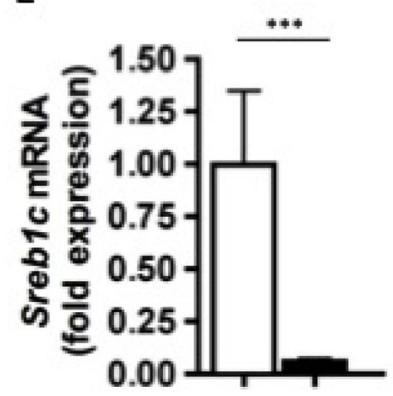

C

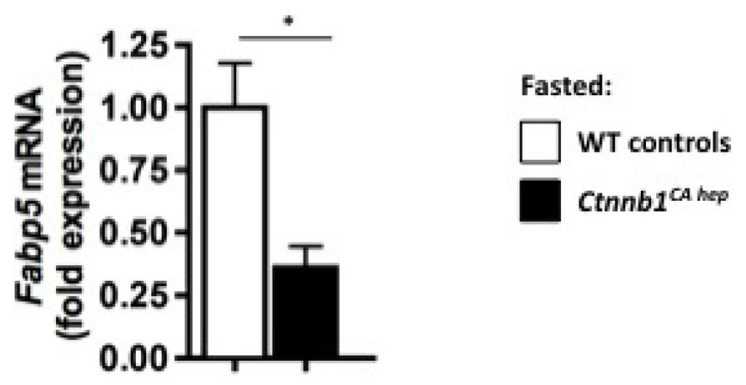

$\mathbf{F}$

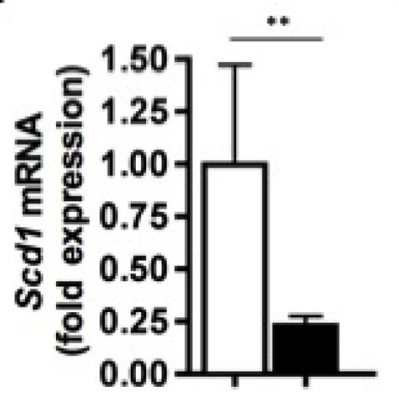

G

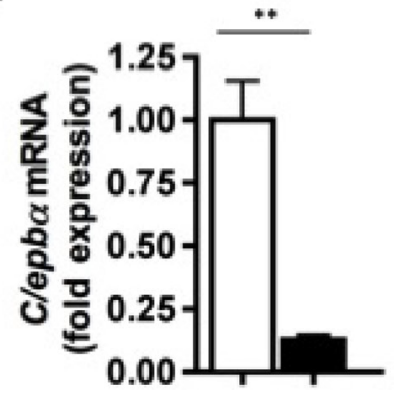

Figure 8: Fasted $C \operatorname{tnn} b 1^{C A}$ hep mice display aggravated down regulation of key enzymes of lipid metabolism. Fatty acid synthase (Fasn; A), fatty acid binding proteins 1 (Fabp1; B) and 5 (Fabp 5 ; C) microsomal triglyceride transfer protein large subunit (Mttp; D), sterol regulatory element binding protein 1c (Sreb1c; E) and stearoyl-CoA desaturase $(\mathrm{Scd} 1 ; \mathbf{F})$ as well as adipogenic transcription factor CCAAT/enhancer binding protein alpha $(\mathrm{C} / \mathrm{ebp} \alpha, \mathbf{G})$ were down-regulated on mRNA level in fasted Ctnnb1 $1^{C A \text { hep }}$ mice compared to their healthy littermates. 
A

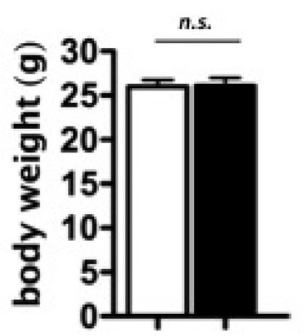

D

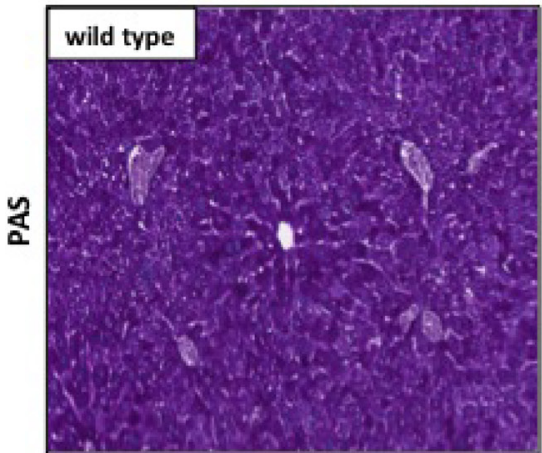

B

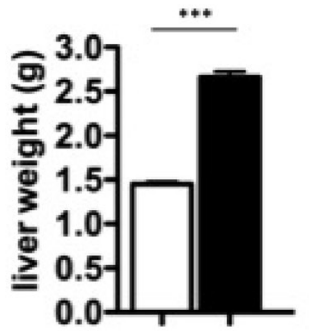

C

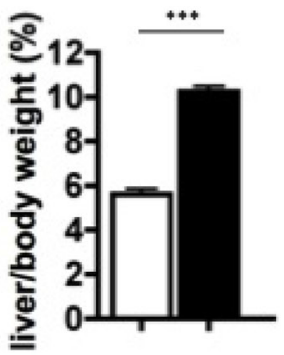

$\mathbf{E}$

$\mathbf{F}$

Figure 9: Ctnnb1 ${ }^{\text {TCCA hep }}$ mice display same metabolic deregulations as Ctnnb1 $^{\text {CA hep }}$ mice. 10-week-old Ctnnb1 $1^{\text {TCCA hep }}$ mice display normal body weight (A) but significantly enlarged livers (B) resulting in a highly increased liver/body weight ratio (C) after induction of continuous $\beta$-catenin signaling. They also display lack of glycogen storage in the liver indicated by PAS staining, lipid accumulation in hepatocytes is indicated by white arrows (D). Serum triglycerides were not changed (E), however serum cholesterol levels were significantly reduced $(\mathbf{F})$.

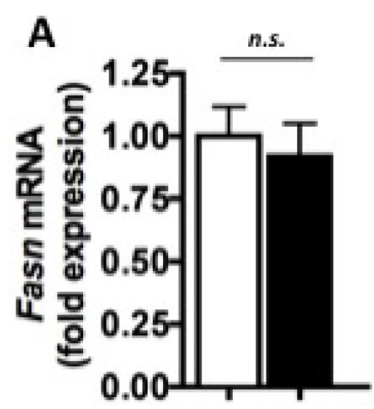

B

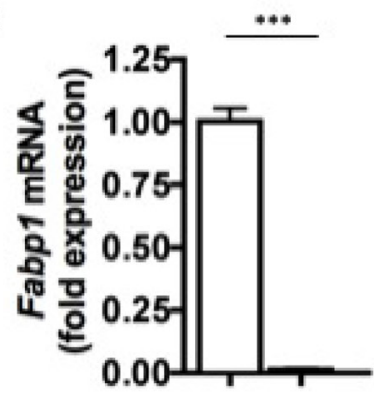

E

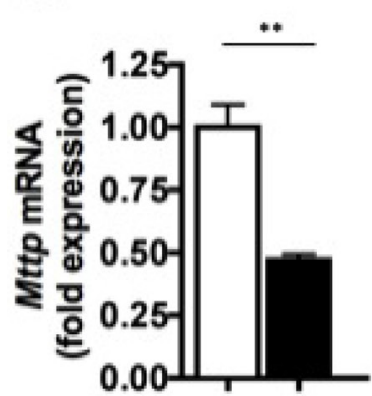

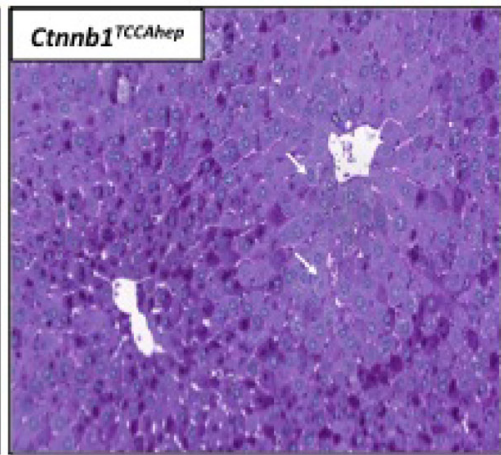
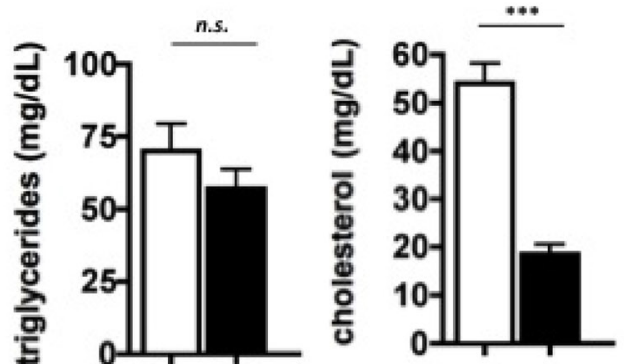

C
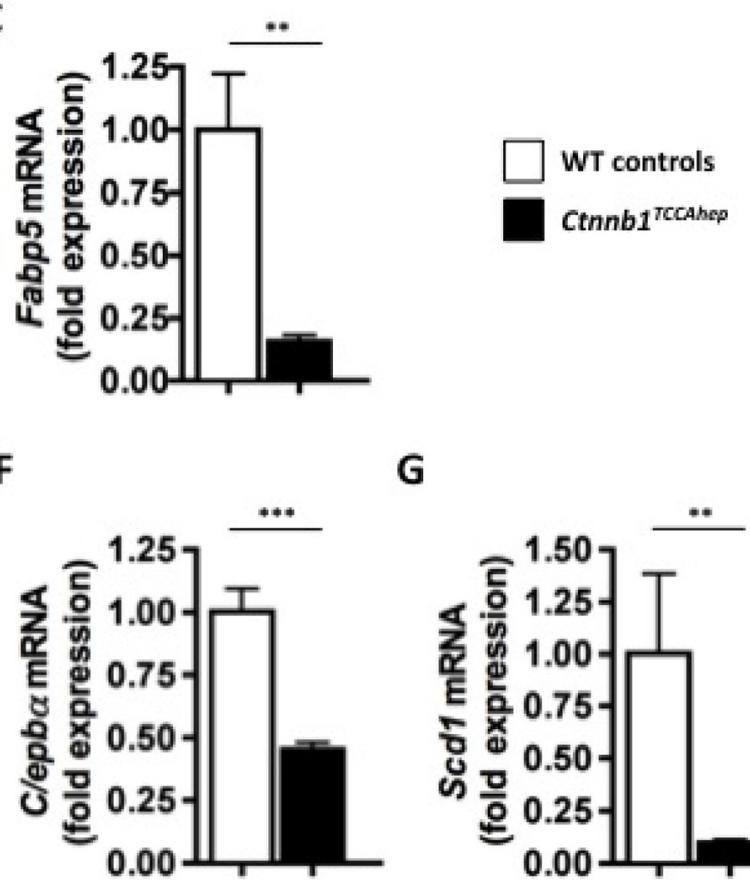

G

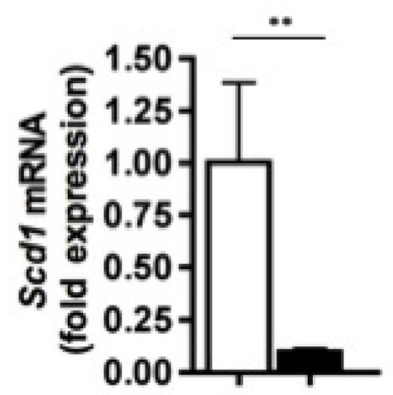

Figure 10: Ctnnb1 ${ }^{\text {TCCA hep }}$ mice display deregulation of key enzymes of lipid metabolism. Fasn; (A), Fabp1 (B), Fabp5 (C), $\operatorname{Mttp}(\mathbf{D}), \operatorname{Sreblc}(\mathbf{E}), \operatorname{Scdl}(\mathbf{F})$ as well as C/ebp $\alpha(\mathbf{G})$ were down-regulated on mRNA level in Ctnnb1 ${ }^{\text {TCCA hep }}$ mice. 
regulation of bile acid/drug metabolism and glutamine synthesis pathway combined with a down- regulation of glucose, lipid and amino acid catabolism and an energetic shift towards anaerobic glycolysis [13, 37]. In fact the top $5 \mathrm{up} /$ down-regulated proteins in our liver proteomics analysis are the same as observed in $A p c \mathrm{KO}$ mice. Although the phenotype of $A p c \mathrm{KO}$ mice was similar, these mice displayed increased glucose uptake demonstrated via a glucose analogue tracer 2-[18F]-FDG [38]. Therefore truncated $\beta$-catenin might directly interfere with proteins involved in glucose metabolism.

In summary, our study provides further evidence linking $\beta$-catenin signaling to metabolic deregulation and down-regulation of genes involved in energy-producing processes as observed in a subgroup of liver cancer patients, especially in the pediatric subtype of liver cancer.

However, further studies are necessary to understand the impact and complexity of continuous $\beta$-catenin signaling in hepatocytes.

\section{MATERIALS AND METHODS}

\section{Mice}

Ctnnb1 $1^{\text {CA hep }}$ and $C t n n b 1^{\text {TCCAhep }}$ mice were generated as described before [21]. All Ctnnb1 ${ }^{\text {CA hep }}$ mice were sacrificed at the age of 21 days. Ctnnb1 $1^{\text {TCCAhep }}$ mice were injected with tamoxifen at the age of 10 weeks and sacrificed 12 days afterwards.

Cre-negative littermates were exclusively used as controls throughout the entire study. All experiments performed in this study were approved by the local ethical committee (BMWFW-66.009/0134-WF/V/3b/2015).

\section{Serum parameters}

Serum parameters were quantified using standard methods as described previously [39].

\section{Histology}

Liver tissue was processed as described previously [21]. Toluidine blue staining, H\&E and Periodic acidSchiff (PAS) staining were performed using standard protocols. Detailed protocols for each staining will be provided upon request.

\section{Quantitative real-time PCR}

Total cellular RNA was isolated using TRI ${ }^{\circledR}$ Reagent RNA Isolation Reagent (Sigma Aldrich) from snap frozen liver tissue following the instructions of the manufacturer. Complementary DNA (cDNA) was generated from $2 \mu \mathrm{g}$ of total RNA using the High Capacity cDNA Reverse Transcription Kit (Applied Biosystems) following the instructions of the manufacturer. $\mathrm{iQ}^{\mathrm{TM}} \mathrm{SYBR}^{\circledR}$ Green Supermix (BioRad) was used for quantitative PCR (qPCR).
Primer sequences were obtained from the qPrimerDepot (http://mouseprimerdepot.nci.nih.gov) and will be provided upon request. Melting curve analysis and agarose gel electrophoresis was performed to assess the quality of primers and the qPCR.

\section{Proteomics}

For whole liver proteomic analysis 3 Ctnnb1 ${ }^{\text {CA hep }}$ mice and 3 WT littermates were harvested at the age of 20 days and livers were snap frozen in liquid nitrogen. $2 \mathrm{mg}$ of tissue were homogenized with an ultrasonic homogenizer in Sample Buffer (Urea, Thiourea, CHAPS, SDS, DTT). Then the solution was digested with trypsin.

Proteins were detected by LC (UltiMateTM 3000 RSLCnano) - MS/MS (QExactive Orbitrap) as described before [40]. Obtained data were evaluated by $T$-test ( $\mathrm{t} 2$ test to consider the variance between groups (difference of mean) but also the variance within groups. Values of $p<0.05$ and $0.58 \log 2$ fold change were considered significant.

\section{Data analysis}

Proteomic data was analyzed using Ingenuity ${ }^{\circledR}$ Pathway Analysis (IPA; http://www.ingenuity.com).

\section{Abbreviations}

AOX: Fatty acyl-coenzyme oxidase; CPT1: Carnitine palmitoyltransferase; CTNNB1: $\beta$-catenin (cadherinassociated protein) beta 1; FA: Fatty acid; FABP: Fatty acid binding protein; FASN: Fatty acid synthase; FBP1: Fructose 1,6-bisphosphatase; GLUT2: Glucose transporter 2; GSK-3 3 : glycogen synthase kinase-3 $\beta$; GYS2: Glycogen synthase; $\mathrm{H}$ and $\mathrm{E}$ : hematoxylin and eosin; $\mathrm{HB}$ : Hepatoblastoma; HCC: Hepatocellular carcinoma; HDL: High-density lipoprotein; LDL: Low-density lipoprotein; MTTP: Microsomal triglyceride transfer protein; PFKL: Liver-specific phosphofructokinase; PPAR $\alpha$ : Peroxisome proliferator-activated receptor alpha; PYGL: Liver specific glycogen phosphorylase; SCD1: Stearoyl CoA desaturase 1; SREBP-1c: Sterol-regulatory element-binding protein-1c; WAT: white adipose tissue; WT: wild type.

\section{Autor contribution}

Ursula Lemberger: Project planning, lab work, breeding and harvest of mice, preparation of the manuscript; Claudia Fuchs: Lab work; Christian Schöfer: Electron microscopy; Andrea Bileck, Christopher Gerner: Liver Proteomics; Tatjana Stojakovic: Serum analysis; Makoto M. Taket: Providing the Ctnnb1 exon 3 flox/ flox mouse; Michael Trauner: Funding and supervision; Gerda Egger: Funding and supervision; Christoph H. Österreicher: Supervision and project planning. 


\section{ACKNOWLEDGMENTS}

We thank Sigurd Krieger (Clinical Institute of Pathology, MUW) for his intellectual input and vivid discussion on metabolism and data interpretation, Barbara Maurer (Ludwig Boltzmann Institute Cancer Research) for her help with the blood glucose analysis, Daniela Milovanovic for her help with histlogy and Prof. Dr. Ingrid Simonitsch-Klupp (Clinical Institute of Pathology, MUW) for her aid with histological findings.

\section{CONFLICTS OF INTEREST}

The authors declare no conflicts of interest regarding this manuscript.

\section{FUNDING}

This work was supported by grants from the Herzfelder'sche Familienstiftung, and the Austrian Science Foundation (FWF) to MT (SFB35; F3517-B20) and GE (P27616-B20).

\section{REFERENCES}

1. Micsenyi A, Tan X, Sneddon T, Luo JH, Michalopoulos GK, Monga SP. Beta-catenin is temporally regulated during normal liver development. Gastroenterology. 2004; 126:1134-46. https://doi.org/S0016508503021474.

2. Tan XP, Monga SP. beta-Catenin is essential in normal liver growth, regeneration and function. Faseb Journal. 2006; 20:A1090-A.

3. Thompson MD, Monga SP. WNT/beta-catenin signaling in liver health and disease. Hepatology. 2007; 45:1298-305. https://doi.org/10.1002/hep.21651.

4. Tan X, Yuan Y, Zeng G, Apte U, Thompson MD, Cieply B, Stolz DB, Michalopoulos GK, Kaestner KH, Monga SP. Beta-catenin deletion in hepatoblasts disrupts hepatic morphogenesis and survival during mouse development. Hepatology. 2008; 47:1667-79. https://doi.org/10.1002/ hep. 22225.

5. Yeh TH, Krauland L, Singh V, Zou B, Devaraj P, Stolz DB, Franks J, Monga SP, Sasatomi E, Behari J. Liverspecific beta-catenin knockout mice have bile canalicular abnormalities, bile secretory defect, and intrahepatic cholestasis. Hepatology. 2010; 52:1410-9. https://doi. org/10.1002/hep.23801.

6. Preziosi ME, Singh S, Valore EV, Jung G, Popovic B, Poddar M, Nagarajan S, Ganz T, Monga SP. Mice lacking liver-specific beta-catenin develop steatohepatitis and fibrosis after iron overload. J Hepatol. 2017; 67:360-9. https://doi.org/10.1016/j.jhep.2017.03.012.

7. Nejak-Bowen KN, Monga SP. Beta-catenin signaling, liver regeneration and hepatocellular cancer: sorting the good from the bad. Semin Cancer Biol. 2011; 21:44-58. https:// doi.org/10.1016/j.semcancer.2010.12.010.

8. Nejak-Bowen KN, Thompson MD, Singh S, Bowen WC Jr, Dar MJ, Khillan J, Dai C, Monga SP. Accelerated liver regeneration and hepatocarcinogenesis in mice overexpressing serine-45 mutant beta-catenin. Hepatology. 2010; 51:1603-13. https://doi.org/10.1002/hep.23538.

9. Guzman M, Castro J. Zonation of fatty acid metabolism in rat liver. Biochem J. 1989; 264:107-13.

10. Jungermann K, Thurman RG. Hepatocyte heterogeneity in the metabolism of carbohydrates. Enzyme. 1992; 46:33-58.

11. Burke ZD, Reed KR, Phesse TJ, Sansom OJ, Clarke AR, Tosh D. Liver zonation occurs through a betacatenin-dependent, c-Myc-independent mechanism. Gastroenterology. 2009; 136:2316-24 e1-3. https://doi. org/10.1053/j.gastro.2009.02.063.

12. Colletti M, Cicchini C, Conigliaro A, Santangelo L, Alonzi T, Pasquini E, Tripodi M, Amicone L. Convergence of Wnt signaling on the HNF4alpha-driven transcription in controlling liver zonation. Gastroenterology. 2009; 137:660-72. https://doi.org/10.1053/j.gastro.2009.05.038.

13. Gougelet A, Torre C, Veber P, Sartor C, Bachelot L, Denechaud PD, Godard C, Moldes M, Burnol AF, Dubuquoy C, Terris B, Guillonneau F, Ye T, et al. T-cell factor 4 and beta-catenin chromatin occupancies pattern zonal liver metabolism in mice. Hepatology. 2014; 59:2344-57. https://doi.org/10.1002/hep.26924.

14. Behari J, Yeh TH, Krauland L, Otruba W, Cieply B, Hauth B, Apte U, Wu T, Evans R, Monga SP. Liver-specific beta-catenin knockout mice exhibit defective bile acid and cholesterol homeostasis and increased susceptibility to dietinduced steatohepatitis. Am J Pathol. 2010; 176:744-53. https://doi.org/10.2353/ajpath.2010.090667.

15. Liu S, Yeh TH, Singh VP, Shiva S, Krauland L, Li H, Zhang P, Kharbanda K, Ritov V, Monga SP, Scott DK, Eagon PK, Behari J. beta-catenin is essential for ethanol metabolism and protection against alcohol-mediated liver steatosis in mice. Hepatology. 2012; 55:931-40. https://doi. org/10.1002/hep.24766.

16. Logan CY, Nusse R. The Wnt signaling pathway in development and disease. Annu Rev Cell Dev Biol. 2004; 20:781-810. https://doi.org/10.1146/annurev. cellbio.20.010403.113126.

17. de La Coste A, Romagnolo B, Billuart P, Renard CA, Buendia MA, Soubrane O, Fabre M, Chelly J, Beldjord C, Kahn A, Perret C. Somatic mutations of the beta-catenin gene are frequent in mouse and human hepatocellular carcinomas. Proc Natl Acad Sci U S A. 1998; 95:8847-51.

18. Guichard C, Amaddeo G, Imbeaud S, Ladeiro Y, Pelletier L, Maad IB, Calderaro J, Bioulac-Sage P, Letexier M, Degos F, Clement B, Balabaud C, Chevet E, et al. Integrated analysis of somatic mutations and focal copy-number changes identifies key genes and pathways in hepatocellular carcinoma. Nat Genet. 2012; 44:694-8. https://doi. org/10.1038/ng.2256. 
19. de La Coste A, Romagnolo B, Billuart P, Renard CA, Buendia MA, Soubrane O, Fabre M, Chelly J, Beldjord C, Kahn A, Perret C. Somatic mutations of the beta-catenin gene are frequent in mouse and human hepatocellular carcinomas. Proceedings of the National Academy of Sciences of the United States of America. 1998; 95:8847-51.

20. Cieply B, Zeng G, Proverbs-Singh T, Geller DA, Monga SP. Unique phenotype of hepatocellular cancers with exon-3 mutations in beta-catenin gene. Hepatology. 2009; 49:82131. https://doi.org/10.1002/hep.22695.

21. Lemberger UJ, Fuchs CD, Karer M, Haas S, Stojakovic T, Schofer C, Marschall HU, Wrba F, Taketo MM, Egger G, Trauner M, Osterreicher CH. Hepatocyte specific expression of an oncogenic variant of beta-catenin results in cholestatic liver disease. Oncotarget. 2016; 7:86985-98. https://doi.org/10.18632/oncotarget.13521.

22. Ross SE, Hemati N, Longo KA, Bennett CN, Lucas PC, Erickson RL, MacDougald OA. Inhibition of adipogenesis by Wnt signaling. Science. 2000; 289:950-3.

23. Ward PS, Thompson CB. Metabolic reprogramming: a cancer hallmark even warburg did not anticipate. Cancer Cell. 2012; 21:297-308. https://doi.org/10.1016/j. ccr.2012.02.014.

24. Pate KT, Stringari C, Sprowl-Tanio S, Wang K, TeSlaa T, Hoverter NP, McQuade MM, Garner C, Digman MA, Teitell MA, Edwards RA, Gratton E, Waterman ML. Wnt signaling directs a metabolic program of glycolysis and angiogenesis in colon cancer. EMBO J. 2014; 33:1454-73. https://doi.org/10.15252/embj.201488598.

25. Lemberger UJ, Fuchs CD, Karer M, Haas S, Stojakovic T, Schofer C, Marschall HU, Wrba F, Taketo MM, Egger G, Trauner M, Osterreicher $\mathrm{CH}$. Hepatocyte specific expression of an oncogenic variant of beta-catenin results in cholestatic liver disease. Oncotarget. 2016; 7:86985-98. https://doi.org/10.18632/oncotarget.13521.

26. Rebouissou S, Franconi A, Calderaro J, Letouze E, Imbeaud S, Pilati C, Nault JC, Couchy G, Laurent A, Balabaud C, Bioulac-Sage P, Zucman-Rossi J. Genotypephenotype correlation of CTNNB1 mutations reveals different ss-catenin activity associated with liver tumor progression. Hepatology. 2016; 64:2047-61. https://doi. org/10.1002/hep.28638.

27. Crippa S, Ancey PB, Vazquez J, Angelino P, Rougemont AL, Guettier C, Zoete V, Delorenzi M, Michielin O, Meylan E. Mutant CTNNB1 and histological heterogeneity define metabolic subtypes of hepatoblastoma. EMBO Mol Med. 2017; 9:1589-604. https://doi.org/10.15252/ emmm.201707814

28. Bandsma RH, Smit GP, Kuipers F. Disturbed lipid metabolism in glycogen storage disease type 1. Eur J Pediatr. 2002; 161:S65-9. https://doi.org/10.1007/ s00431-002-1007-8.
29. Bianchi L. Glycogen storage disease I and hepatocellular tumours. Eur J Pediatr. 1993; 152:S63-70.

30. Calderaro J, Nault JC, Bioulac-Sage P, Laurent A, Blanc JF, Decaens T, Zucman-Rossi J. ALDH3A1 is overexpressed in a subset of hepatocellular carcinoma characterised by activation of the Wnt/ss-catenin pathway. Virchows Arch. 2013; 464:53-60. https://doi.org/10.1007/ s00428-013-1515-0.

31. Ma K, Saha PK, Chan L, Moore DD. Farnesoid X receptor is essential for normal glucose homeostasis. J Clin Invest. 2006; 116:1102-9. https://doi.org/10.1172/JCI25604.

32. Bandsma RH, Rake JP, Visser G, Neese RA, Hellerstein MK, van Duyvenvoorde W, Princen HM, Stellaard F, Smit GP, Kuipers F. Increased lipogenesis and resistance of lipoproteins to oxidative modification in two patients with glycogen storage disease type 1a. J Pediatr. 2002; 140:25660. https://doi.org/10.1067/mpd.2002.121382.

33. Jiang J, Nilsson-Ehle P, Xu N. Influence of liver cancer on lipid and lipoprotein metabolism. Lipids Health Dis. 2006; 5:4. https://doi.org/10.1186/1476-511X-5-4.

34. Fattman CL, Schaefer LM, Oury TD. Extracellular superoxide dismutase in biology and medicine. Free Radic Biol Med. 2003; 35:236-56.

35. Han D, Kaplowitz N. Mitochondria in Liver Disease. 1st Edition; CRC Press. 2016.

36. Lehwald N, Tao GZ, Jang KY, Papandreou I, Liu B, Pysz MA, Willmann JK, Knoefel WT, Denko NC, Sylvester KG. beta-Catenin regulates hepatic mitochondrial function and energy balance in mice. Gastroenterology. 2012; 143:754-64. https://doi.org/10.1053/j.gastro.2012.05.048.

37. Chafey P, Finzi L, Boisgard R, Cauzac M, Clary G, Broussard C, Pegorier JP, Guillonneau F, Mayeux P, Camoin L, Tavitian B, Colnot S, Perret C. Proteomic analysis of beta-catenin activation in mouse liver by DIGE analysis identifies glucose metabolism as a new target of the Wnt pathway. Proteomics. 2009; 9:3889-900. https://doi. org/10.1002/pmic.200800609.

38. Benhamouche S, Decaens T, Godard C, Chambrey R, Rickman DS, Moinard C, Vasseur-Cognet M, Kuo CJ, Kahn A, Perret C, Colnot S. Apc tumor suppressor gene is the "zonation-keeper" of mouse liver. Dev Cell. 2006; 10:759-70. https://doi.org/10.1016/j.devcel.2006.03.015.

39. Jha P, Knopf A, Koefeler H, Mueller M, Lackner C, Hoefler G, Claudel T, Trauner M. Role of adipose tissue in methionine-choline-deficient model of non-alcoholic steatohepatitis (NASH). Biochim Biophys Acta. 2014; 1842:959-70. https://doi.org/10.1016/j.bbadis.2014.02.012.

40. Slany A, Bileck A, Kreutz D, Mayer RL, Muqaku B, Gerner C. Contribution of Human Fibroblasts and Endothelial Cells to the Hallmarks of Inflammation as Determined by Proteome Profiling. Mol Cell Proteomics. 2016; 15:198297. https://doi.org/10.1074/mcp.M116.058099. 